\title{
Lexical Phrases: An Essential Brain-Adaptive Requisite for Second Language Acquisition
}

\author{
Nermin Hosny Yusuf \\ English and Scientific Methods Department \\ German University in Cairo \\ El Tagamoa El Khames, New Cairo, Egypt \\ E-mail: nermin.yusuf@yahoo.com
}

Received: April 5, 2020

Accepted: June 19, 2020

Published: June 27, 2020

doi:10.5296/ijl.v12i3.17260

URL: https://doi.org/10.5296/ijl.v12i3.17260

\begin{abstract}
In the incessant attempts to overcome second language (L2) acquisition difficulties and to improve second language proficiency, most of the proposed methodological approaches which address this issue place high value on individual vocabulary and grammar of a second language and fall short of integrating lexical phrases/multi-unit expressions into the teaching approaches. This, if does not exacerbate acquisition difficulties, does not by any means improve it. On this view, the ubiquitous interest in lexical phrases gave rise to their investigation in language acquisition. This paper reviews the importance of lexical phrases in language acquisition by providing further insight into their peripheral role in first language and second language acquisition alike. Also, Evidence from neurolinguistic and psycholinguistic studies are provided to account for lexical phrases representation and brain-adaptability. Further, this paper suggests the implementation of lexical phrases, in general, and the Lexical Approach, in particular, in second language acquisition. Finally, further pedagogical implications as well as self-paced ones are proposed.
\end{abstract}

Keywords: Lexical phrases, Formulaic sequences, Mental lexicon, L2 acquisition, Collocations

\section{Overview}

It is widely noted that attaining a second language (L2) is not comparable to attaining a first language (L1) with respect to proficiency as well as the level of difficulty an L2 learner encounters. Unlike L1, a language learner is usually troubled with respect to learning an L2 
especially after childhood. Second language learners in general, and late learners in particular, usually find it more effortful to learn and use their L2 than their L1 (Segalowitz, Segalowitz $\&$ Wood, 1998). To this end, numerous teaching approaches and methodologies have been proposed to meet the said purpose. However, to date, L2 learners -even advanced ones- face difficulties in using target language appropriately. This is largely due to L2 learners' failure in using target language lexical phrases (formulaic sequences / conventionalized prefabricated patterns) (Hoang \& Bores, 2016; Laufer \& Waldman, 2011; Levitzky-Aviad \& Laufer, 2013; Serrano, Stengers \& Housen, 2015; Yusuf, 2016). This failure may be attributed to L2 learners' attentiveness to target language individual vocabulary, in contrast to L1 acquisition process, rather than larger chunks (lexical phrases) (Wray, 2002).

\section{What Are Lexical Phrases?}

Lexical phrases are referred to in the literature in a plathora of terms such as lexical chunks, formulaic expressions/sequences, lexical bundles, conventionalized language, pre-fabricated language/patterns, lexicalized sentences, institutional sentences, phraseogical units and multi-word units. Lexical phrases have started to draw the attention of linguists as early as 1974 with several definitions provided thereof with reference to their prefabrication and memory predominance.

As early as 1974, Hakuta defined lexical phrases as prefabricated memorized patterns which may consist of certain frames with open gaps that give a space for creation by filling such gaps with different forms. Similarly, Siyanova-Chanturia, Conklin, and Schmitt (2011) assert that lexical phrases are prefabricated sequences which could be continuous or discontinuous and which are stored and retrieved from memory.

In a similar vein, Nattinger and DeCarrico (1992) defined lexical phrases as "conventionalized form/function composites that occur more frequently and have more idiomatically determined meaning than language that is put together each time" (p. 1). Along the same line, Wray (2002) posits that lexical phrases are "a sequence, continuous or discontinuous, of words or other meaning elements, which is, or appears to be, prefabricated: that is, stored and retrieved whole from memory at the time of use, rather than being subject to generation or analysis by the language grammar" (p. 9).

Consistent with the previous definitions, Nesselhauf (2005) incorporates such whole-phrase-unit concept in her reference to collocations stating that:

A verb-noun collocation is not only understood as comprising a verb and a noun but also the central determiners, noun complementation structures and so forth that are present. All elements in an expression such as come to the conclusion that would therefore be considered to belong to the collocation, and deviations in any of these elements are considered to be deviations in the collocation (p. 71).

In like-manner, Biber (2007, p. 990) regards lexical phrases, to which he refers to as lexical bundles, as extended collocations. Biber defines lexical bundles as "sequences of word forms that commonly go together in natural discourse" and, further, lists them under grammar 
stating that grammar is not only concerned with studying abstract classes and structures, but is also concerned with studying the particular functions of particular words.

Lexical phrases, at one end of the spectrum, can be fixed such as by the way in which the word by, for example, cannot be replaced by other words like off or beside. In contrast, other lexical phrases allow variability such as if I were you in which the word you could be replaced by other words like the king or the president. Similarly, the word coincidence in the phrase by pure coincidence can only be replaced by limited words like chance but not by other words like accident or fortune (Nattinger \& DeCarrico, 1992). At the other end of the spectrum, lexical phrases are comprised of at least two words frequently used and preferred by native speakers rather than any other possible alternative which equates the prefab meaning. In this regard, "it is idiomatic to say as a result of and as a consequence of, but not the equally grammatical and comprehensible as the aftermath of or as a repercussion of" (Wray, 2002, p. 87).

The importance of lexical phrases lies in the fact that they constitute more than $50 \%$ of natives speakers' production of spoken and written language according to Erman and Warren (2000) and Wray (2002). It is worth noting here that the importance of lexical phrases also stem from the fact that they are brain-adaptable; on this account, below, evidence from neurolinguistic as well as psycholinguistic studies is provided.

\section{Lexical Phrases Are Brain-Adaptive}

For long, learning methodologies and approaches as well as L2 theories have ignored adapting to the equipotential nature of the two hemispheres of the brain. To clarify, it has always been assumed that the left hemisphere is the one adept at learning an L2 whereas the right hemisphere was underrated; therefore, only the analytical skills of the left hemisphere were targeted in learning an L2. This has been a hallmark in the learning process.

Several researchers postulate that the linguistic brain is of a dual nature. On this view, Sinclair (1991) argues that two main principles are utilized in handling linguistic material, namely the open choice principle and the idiom principle. In the open choice principle, a speaker uses individual words to produce speech. Whereas, in the idiom principle, a string of words, which is of previous and frequent occurrence, is retrieved. In the same vein, like Sinclair, Wray (1992) proposes a dual-system approach to language; to this end, the first system is an analytic one in which an interaction of words and grammatical rules occur; resultantly, this system analyzes and decodes novel linguistic material. The second system is of a holistic nature where prefabricated sequences are stored and retrieved from the memory. This holistic system, unlike the analytic system but complementary to it, though incapable of decoding nor analyzing new information, is formulae-adaptive. Congruent with these views, according to Code (1994), it is implausible to produce speech with such an efficiency and rapidity were speakers to handle each segment individually. Seemingly there are two systems that underlie speech, namely closed-loop and open-loop. In closed-loop, each language segment is planned and produced; however, in open-loop, the whole chunks are pre-planned, retrieved and produced automatically. 


\section{Mll Macrothink}

International Journal of Linguistics

ISSN 1948-5425

2020, Vol. 12, No. 3

The dual-system view is further supported by numerous studies with various techniques which highlight the lexical-phrases adaptive brain as well as the contribution of the right hemisphere to language acquisition in general, and to lexical phrases acquisition in particular.

\subsection{Brain Adaptability: Neurolinguistic Evidence From Aphasia Studies}

In an early study, Scarcella and Karshen (1978) dispute that automatic speech resides in both hemispheres unlike propositional language which is represented mainly in the left hemisphere. They support their argument by evidence from aphasia stating that in cases of non-fluent aphasia, patterns and routines are preserved contrasting to propositional language. Also, in cases of adult-left-hemispheroctomy (surgical removal of one of the two cerebral hemispheres), patients have shown the ability to retrieve patterns and routines despite their inability to produce language freely. In congruence with this view, Wray (1992) asserts that some aphasia studies show that post left hemisphere lesions, which lead to loss of communication ability, automatic phrases have remained intact. She, further, argues in support of the pivotal role of the right hemisphere stating that it is highly adept at applying sets of formulae as well as responsible for automatic speech. On this account, Wray concludes that the right-hemisphere contributes to language in a non-analytical way. In effect, the right-hemisphere, which is more adept at holistic perception, contributes, in addition to intonation and gestures, to automatic speech in the communication process.

In more recent studies, Sidtis, Canterucci and Katsnelson (2009) noted that left-hemisphere damaged patients preserved the ability to produce formulaic expressions unlike right-hemisphere-dagmaged patients who lacked such an ability. In a latter study which investigated the role of the right hemisphere in comprehension and production of formulaic expressions, Van Lancker and Yang (2017) examined unilateral right- and left-brain damaged patients, who were given various tasks involving formulaic expressions. Their findings supported the right hemisphere's involvement in processing formulaic expressions.

\subsection{Brain Adaptability: Evidence in Reference to Psycholinguistics}

\subsubsection{The Mental Lexicon}

There seems to be a consensus that words are not haphazardly represented in the human brain (i.e. the mental lexicon); rather, they are of definite organization. Anecdotally, the efficiency of human beings to use language and find targeted words among other enormous amount of words is indicative of the organization of words in the human brain (Gairns, 1986). In light of this, Bonin (2004) posits that several representations characterize the organization of the mental lexicon such as phonological, semantic and morphological ones. In like manner, Levelt (1995) asserts that the mental lexicon has four main features for organizing words, namely semantic, syntactic, morphological and phonological features. In parallel, and with particular reference to lexical phrases, Pinker (1999) refers to the organization of words in the lexicon stating that multi-word units are represented and memorized as a whole. In a similar fashion, lexical phrases (multi-word units) are argued to be categorized alongside individual words in the lexicon (Bybee, 2006) and to be stored in long term memory in a network rather than individually (Bruza et al., 2009). 
In line with the storage of lexical phrases as whole units in the memory, Wray (2002) postulates that when lexical phrases are learned as wholes with no analysis to details, they are stored as holes in the memory and unless they are used regularly, they are prone to fade. In a similar fashion, Lewis (2008) posits that words are stored in the memory in the form of pre-fabricated chunks. His rationale is that collocation is of an arbitrary nature:

High/tall building, tall boy but not * high boy. Prices rise and fall; you can rise to the occasion but not *fall to the occasion. You can look at a person or problem; you can gaze at a person but not at a problem. This non-generalisability clearly indicates that we meet and store words in the prefabricated chunks upon which the Lexical Approach is based (p. 26).

\subsubsection{Eye-Tracking Technique}

Technological advancements have provided the emergence of a seminal technique in studying psycholinguistic aspects of language, namely eye-tracking technique. In eye-tracking technique, an eye-tracking program is used where participants are seated facing a monitor and a head-mounted camera for pupil movement eye-tracking. Eye-tracking provides "an online way to examine how words are recognised, processed and integrated into sentence structures, and to explore the various factors that affect these processes such as frequency, length, ambiguity and other variables" (Carrol \& Conklin, 2014, p. 1). Presumably, when the eye fixates on a certain word, the word is being processed in the brain which is an indication of the cognitive efforts involved and the un-familiarity of the sequence presented. On the other hand, when the eye skips a word, it is perceived as an indication of the familiarity and predictability of the word. In this case, the sequences of predicted words are concluded to be represented holistically in the mental lexicon.

In a recent study conducted by Carrol and Conklin (2015), eye-tracking was used to explore the representation of formulaic sequences in the mental lexicon. To this end, Chinese-English Bilinguals were introduced to English-translated Chinese idioms as well as non-idiomatic control phrases. The aim behind this experiment was to explore if learners read the translated idioms the same way they read the control phrases. In other words, it was investigated if the idioms are processed with more speed than the control phrases. The findings suggest that idioms are recognized and processed with more facilitation than non-idiomatic forms even when the idiom is processed in its L2 translated form. In similar-technique studies, it was found that lexical phrases/idioms are processed faster than non-idiomatic formulas even if the control phrases contain the same words, yet in a non-idiomatic sequence (Siyanova-Chanturia et al., 2011; Underwood, Schmitt \& Galpin, 2004).

The above findings are suggestive of the holistic processing of lexical phrases and their storage as units in the mind. The familiarity with a sequence of words facilitates its processing and production; hence, familiarity with formulaic sequences lessens the brain processing effort and processing time; in consequence, being familiar with lexical phrases is postulated to enhance L2 learners' performance and fluency. 


\section{Lexical Phrases and Language Acquisition}

Lexical phrases are pivotal and characterize the acquisition process of L1 and L2 alike. Anecdotally, Lewis (1993) argues that language acquisition does not occur by learning individual words and assembling such words together; contrarily, language is acquired by learning whole phrases and, then, analyzing them into constituents. In like manner, Nesselhauf (2005) notes that lexical chunks are essential in L2 learning as they have been proven to have a pivotal role in both L1 and L2 acquisition; they further, play an important role in improving the fluency in spoken and written language as well as supporting comprehension of a language.

\subsection{Lexical Phrases and First Language Acquisition}

In first language acquisition studies, it was noted that pre-fabricated patterns characterize children's acquisiton. Scarcella and Karshen (1978), point out that one possible explanation for the relationship between prefabricated patterns and language acquisition is that prefabricated patterns pave the way for language acquisition process to re-analyze them and use their constituents creatively in new language constructions. For example, Brown (1973) noted that his participants memorized whole patterns to which he attributed to the high frequency input of language structure that is beyond the linguistic abilities of the children. Similarly, Clark (1974), in her research findings, suggested that child's speech "becomes creative through the gradual analysis of the internal structure of sequences which begin as prepackaged routines" (p. 9). Likewise, Pawly and Syder (1983) posit that fluent native-like language is highly dependant on fixed/semi-fixed expressions which they referred to as lexicalized sentences, institutional sentence, formulaic sentence, or phraseogical units. Moreover, in a recent study, Daloiso (2009) affirms the frequent use of prefabricated language in the learning process of young children. They state that children have the ability to memorize whole chuncks of sentences and use/reuse them in their appropriate contexts. This occurs in the procedural memory which organizes the input in an unconcious and automatic nature.

\subsection{Lexical Phrases and Second Language Learning}

In second language acquisition, pre-fabricated patterns seem to be very important in underlying the language fundametals and in leading, eventually, to aquiring an L2. Nattinger and DeCarrico (1992, p. 59) assert that learning a second language is not restricted to "isolated bits of grammatical structure", but also must involve learning whole phrases (lexical phrases) in order to effectively comprehend and converse in this language. Moreover, Biber (2007, p.990) points out that "producing natural idiomatic English is not just a matter of constructing well-formed sentences, but of using well-tried lexical expressions in appropriate places”. Congruent with this, Skehan (2010, p. 351) asserts the importance for an L2 learner to learn formulaic sequences and idiomatic language which "are now seen as pervasive and vital for real-time communication" and which are, thus, postulated to be a major step to achieve a high degree of automatization and control over an L2. 


\section{Macrothink}

International Journal of Linguistics

ISSN 1948-5425

2020, Vol. 12, No. 3

The peripheral role of lexical phrases in language acquisiton lies in their fundamental contribution to attaining a high level of L2 profeciency (Pawly \& Syder, 1983). On this account, and with particular reference to their representation in memory, Ellis (1996) argues that lexical chunks (lexical phrases) are pivotal for language learning in two aspects: first, when they are stored in long-term memory and are liable to recall, they enhance fluency of speech. Second, they aid in improving language proficiency as they provide input for analysis of language rules. Similarly, Chambers (1998) postulates that lexical phrases aid L2 speakers in language production by producing the ready-made lexical chunks while allowing them time to assemble new word combinations to lengthen their speech units. In so doing, a learner's second language proficiency is enhanced. In like-manner, Wood (2001) argues that formulaic sequences widely contribute to improving L2 fluency since they are retrieved readily from memory. This provides an opportunity for the speaker to focus their attention on other required simultaneous tasks for language processing.

Hatami (2015), in a more recent view of the issue, states that mastering formulaic sequences plays a pivotal role in achieving communicative competence. By the same token, Arnon, McCauley and Christiansen (2017) assert that multi-word units are cornerstones in language acquisition as they are pivotal in shaping the learner's knowledge about the usage of language and as they provide the learner with the required structural information which connects the words together to form a whole unit.

From a neurological standpoint, it is postulated by Lee (2004) that in as much as a learner uses fixed expressions (lexical phrases), the basal ganglia -a brain subcortical structure responsible, among other functions, for learning - is repeatedly activated. This, in turn, will enhance the learning process and will preclude a step-by-step application of a phrase/grammatical rule. In essence, facing difficulties in L2 grammar acquisition can be overcome by excessive learning of lexical phrases. This suggestion is proposed by Ullman (2005) who asserts that late L2 grammatical acquisition difficulty, in particular, poses a greater difficulty than early L2 acquisition. Ullman attributes this, mainly, to depression of procedural memory - which underlies unconscious learning- abilities, as an adverse effect, due to improvement of, and reliance on, declarative memory -which underlies conscious memory. Hence, Ullman suggests that memorizing complex forms and rules would compensate for the depressed procedural memory and would, further, lead to a high degree of proficiency.

The above-mentioned views are supported by an early study conducted by Hanania and Gradman (1977) which provides insight for the importance of lexical phrases in L2 acquisition through studying the development of their subject's (Fatmah) second language. Fatmah who was a 19-year-old Arabic speaker, commencated her second language learning journey informally in social contexts in the United States. In the beginning of her journy, her language consisted mainly of memorized chuncks which she did not recognize their sigments. However, in a developed stage of her language learning process, she acquired the analytical ability, resembling that of first language acquistion, which enabled her to form new English constructions. 
In a story re-telling task, Hoang and Bores (2016) investigated the possibility of multi-word unit intake. Participants in the experimental group were exposed to a story rich in multi-word expressions through reading and listening to the story twice. They then were asked to re-tell the story in order to detect any acquired expressions. On the other hand, the control group was asked to tell the story based on a series of pictures. Their findings indicate that learners in the experimental group transferred MWU from input to output. In another investigation, Wood (2010) examined the effect of lexical chunks on speech fluency. Participants were provided with an intensive instruction for the formulaic sequences and reproduced them in activities. The participants were then tested by oral narratives which showed an enhanced level of fluency and considerable use of formulaic sequences.

Using a reflective lexical-based-approach, Chandra (2014) investigated learners' acquisition of collocations and lexical phrases. The participants were introduced to reading passages which included a wide array of lexical chunks and collocations. Then, their production of these phrases were tested though descriptive essay writing assignments. On the one hand, the reflective journals showed that the participants widely benefited from the approach by increasing their knowledge in lexical phrases and collocations. On the other hand, the writing assignments showed a range of collocations and lexical phrases which indicates the learners' improvement with regard to their use of collocations and lexical phrases. Further studies such as (Bores et al., 2006; Stengers, Boers, Housen \& Eyckmans, 2010; Wood, 2009; Wood, 2010), where formulaic sequences instruction and practice was applied to L2 learners, also showed enhanced L2 fluency.

Thus, L2 learners should acquire formulaic sequences and learn how to use them appropriately in linguistic and social contexts in order to effectively communicate in L2 (Lewis, 1997). In point of fact, it is essential, hence, to integrate whole-phrase-unit concept (lexical phrases) in L2 teaching materials and approaches.

\section{Lexical Phrases and L2 Teaching}

Lexical phrases are merit teaching and since they characterize language acquisition and performance, they are, ostensibly, pivotal in language teaching (Nattinger \& DeCarrico, 1992). Yet, to date, teaching approaches have failed, to a considerable extent, to integrate lexical chunks into language acquisition. This is because even advanced-level students lack knowledge of lexical chunks. In this regard, studies such as (Altenberg \& Granger, 2001; Laufer \& Waldman, 2011; Li \& Schmitt, 2010; Siyanova \& Schmitt, 2008) provide evidence of non-native speakers' language production failure to show richness of multi-word expressions. This view is also supported by Nesselhauf (2005) who reports that even advanced-level learners in many cases deviate from the correct lexical chunks/collocations and in other cases may create an acceptable lexical chunk/collocation, however use it inappropriately in a way that does not convey its correct meaning. Consequently, Nesselhauf concludes that the length of learners' exposure to English in a classroom does not affect their lexical chunks accuracy due to the inadequate way they are taught with.

Different approaches in teaching L2 lexical chunks in the classroom are, thence, required. In this regard, the author agrees with Nesselhauf's (2005) suggestion that learners' awareness 
should be raised with regard to L2 combinations which are not entirely fixed (i.e. idioms) but rather "arbitrary to some degree" (p. 252). Furthermore, it is of high importance, as suggested by Nesselhauf (2005), to call for explicit teaching of lexical chunks, particularly those which lead to "meaning disruption" and which have different formation in L1 than L2.

\subsection{The Lexical Approach}

Due to the urge of integrating lexical phrases in language teaching, one seminal approach emerged in 1993, the Lexical Approach by Michael Lewis. The Lexical Approach argues that learning a second language is more similar, than different, to learning a first language where lexical phrases should be integrated in the teaching approach (Lewis, 2008). He, further, states that chunks are the foci of a language which a coherent text consists of.

It is highly suggested to implement the lexical approach which, according to Lewis (2008), is categorized into four main constructions (summarized in table 1 below):

Table 1. The lexical approach categories (Lewis, 2008)

\begin{tabular}{|c|c|c|}
\hline Type of Chunk & Definition & Examples \\
\hline 1- Words & $\begin{array}{l}\text { Are the largest category of the lexicon; } \\
\text { basic language units which are listed in } \\
\text { dictionaries. }\end{array}$ & Open / Certainly \\
\hline a. Polywords & $\begin{array}{l}\text { Two- or three-word units, which, like } \\
\text { units, are invariable and indivisible, and } \\
\text { which are mostly, but not exclusively, } \\
\text { adverbial phrases. invariable, indivisible } \\
\text { word-like units }\end{array}$ & $\begin{array}{l}\text { By the way / On the other } \\
\text { hand }\end{array}$ \\
\hline $\begin{array}{l}\text { b. De-lexicalised } \\
\text { words }\end{array}$ & $\begin{array}{l}\text { Words (or verbs) which have little } \\
\text { meaning per se and which are more } \\
\text { meaningful within a context. }\end{array}$ & $\begin{array}{l}\text { Point: Don't point! / I need } \\
\text { something with a sharp point / } \\
\text { I don't think there's much } \\
\text { point. }\end{array}$ \\
\hline 2- Collocations & $\begin{array}{l}\text { Frequently recurring words that are used } \\
\text { together; some of which are fixed while } \\
\text { others are open with a slot which could } \\
\text { be replaceable by a limited number of } \\
\text { words. }\end{array}$ & $\begin{array}{l}\text { Catch a cold } \\
\text { Make a mistake } \\
\text { Miss the bus }\end{array}$ \\
\hline $\begin{array}{l}\text { 3- } \text { Fixed } \\
\text { expressions }\end{array}$ & $\begin{array}{ll}- & \text { Social greetings; } \\
\text { - } & \text { Politeness phrases; } \\
\text { - } & \text { 'Phrase Book' language; } \\
\text { - } & \text { Idioms. }\end{array}$ & $\begin{array}{l}\text { - Good morning / Happy } \\
\text { new year; } \\
\text { - No thank you, I 'm fine; } \\
\text { - Can you tell me the way } \\
\text { to ....... . please; } \\
\text { - you 're putting the cart } \\
\text { before the horse there. }\end{array}$ \\
\hline $\begin{array}{l}\text { 4- Semi-fixed } \\
\text { expressions }\end{array}$ & $\begin{array}{l}\text { Are open with slots with minimal } \\
\text { word-choice variation. }\end{array}$ & $\begin{array}{l}\text { What was really interesting / } \\
\text { surprising / annoying was .... }\end{array}$ \\
\hline
\end{tabular}




\section{Macrothink}

International Journal of Linguistics

ISSN 1948-5425

2020, Vol. 12, No. 3

Lewis (2008) also provides some further suggestions in support of implementing the lexical approach; some of which are mentioned below:

- A notebook should be used in lieu of a traditional vocabulary textbook. In so doing, L2 learners would be discouraged from L1-L2 vocabulary literal translation and, instead, would have a notebook of the noticed lexical phrases they learn including collocations, fixed- and semi-fixed- lexical phrases.

- Teaching chunks which of frequent combinations (i.e. suspicious of people who..., relevant to our discussion/problem/needs) (p. 9) by completion tasks.

- $\quad$ Teaching fixed expressions via sentence re-arranging tasks where a learner recognizes and recalls prefabricated chunks from memory. These tasks could also focus on de-lexicalized words in different contexts.

- Marking possible collocations for several words in a grid where learners are asked to check the possible collocates that go along with a word.

- $\quad$ Raising the learners' awareness of collocations by using a collocation dictionary such as BBI collocation dictionary

- The use of Cobuild's little boxes in which a word/construction is introduced with its possible collocates/complements in the absence of any grammatical analysis. See the following example (p. 39):

\begin{tabular}{|l|l|}
\hline That's & $\begin{array}{l}\text { great. } \\
\text { dreadful. } \\
\text { exciting. } \\
\text { terrifying. }\end{array}$ \\
\cline { 1 - 2 } That sounds & interesting. \\
That must be & marvellous. \\
That must have been & awful. \\
& wonderful. \\
& good fun. \\
\hline
\end{tabular}

- Introducing students to lexical phrases for different functions such as likes/dislikes, giving reasons/explanations/advice, etc.

- Encouraging learners to notice, document and record lexical chunks whereas discourage them from documenting individual words.

- Repetition of tasks and activities so that the learner is exposed to the lexical chunks repeatedly.

- Since L1 influence is mostly inevitable, it would be useful for learners to write L1 equivalents to L2 lexical phrases.

- Short lists of collocates can be useful if they are introduced to learners in the form of boxes. See the example below: 


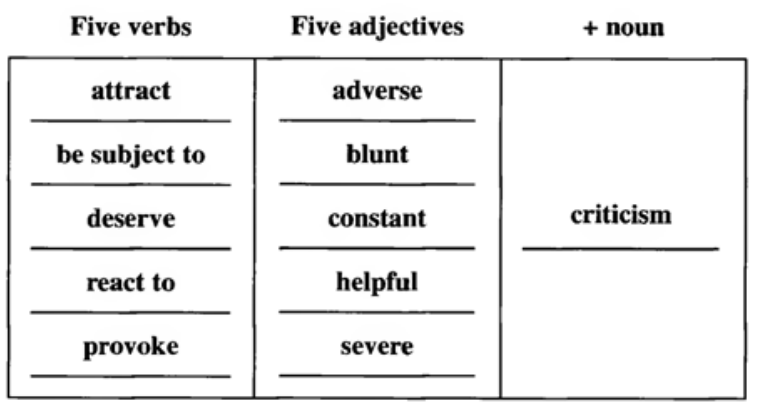

For further suggestions and other specific exercises designed on lexical principles, review Implementing the Lexical Approach by Lewis (2008).

Other suggestions, in light of the lexical approach, for classroom implementation are provided by Ramírez (2012, p. 249) who states that "classroom tasks should be selected to allow the input to become intake and thus, to produce automatic retrieval". The suggestions are as follows:

- Handling with general and specific dictionaries and other reference tools.

- Making vocabulary learning enjoyable and stimulating.

- Guessing the meaning of lexical items from context.

- $\quad$ Using real situations in simulations.

- Working in groups: helps learning independence and exchange knowledge.

- $\quad$ Practicing rhetorical functions.

- Noticing collocations and language patterns.

- $\quad$ Recycling and repetition of tasks.

- Intensive, extensive reading and listening.

- Working with language corpuses.

- A variety of word association games and exercises using the diverse techniques of cloze procedure.

- $\quad$ Further hints through underlining.

\section{Conclusions and Further Suggestions}

This paper provides a further insight to the fact that learning an L2 should not merely depend on learning the individual vocabulary and grammatical rules, it should primarily be based on whole-phrase-unit learning in order to minimize L2 errors. In this paper, a range of definitions for lexical phrases were provided, brain-adaptability- and psycholinguisticevidence were provided; also, memory-related aspects in reference to the mental lexicon were highlighted. Furthermore, this paper tackled first and second language acquisition in relation to lexical phrases as well as lexical phrases in teaching approaches with particular reference 
to the Lexical Approach. Below are further suggested ways by which lexical phrases could be learned.

\subsection{The Use of Corpora}

It is suggested that L2 learners be introduced to native corpora instead of depending mainly on dictionaries. That is, to facilitate L2 lexis and formula acquisition, learners should depend on linguistic corpora along with, if not instead of, dictionaries. This is because one of the major problems of the dictionary view of meaning is the fact that "the dictionary view assumes a sharp distinction between knowledge of word meaning, and knowledge about how contextual factors influence linguistic meaning" (Evans \& Green, 2006, p.209). Recently, due to technological advancements, exposure to L2 lexical phrases is feasible via databases of native language corpora. Examples of native language corpora include: COBUILD Bank of English Corpus, the Cambridge International Corpus (CIC), the British National Corpus (BNC) and the Contemporary American English (COCA). Below, brief description is provided for the later three corpora are provided:

\section{The Cambridge International Corpus (CIC)}

The Cambridge International Corpus (CIC) is accessible via https://www.cambridge.org/elt/corpus/international_corpus.htm and is originally built by Cambridge University Press in order to aid in language learning as well as language investigation. The corpus encompasses a number of corpora including British spoken English, American spoken English, finance-, bussiness- and law-related data, and academic English.

\section{British National Corpus (BNC)}

The British National Corpus (BNC) is accessible via http://www.natcorp.ox.ac.uk/. It is created by Oxford University Press and includes over 100 million words of various genres including newspapers, magazines, fiction, spoken and academic ones. The corpus covers a wide range of geners and provides a pwoerful interface for studdying English phrases up to eight words long via Phrases in English (PIE) http://phrasesinenglish.org/. PIE enables learners to check the frequency of a string of words in English; it is also possible to check for a string of words that includes a missing word, substituted by $(*)$, and provides a great number of variants of such a string. PIE can also present patterns of Part of Speech tags (PoS) such as ART ADJ NOUN as in the other hand and PREP ART NOUN as in at the end.

The British National Corpus is also accessible via https://www.english-corpora.org/bnc/. It is a user-friendly interface which allows a learner to check the availability of whole phrases in the English language; it also allows for checking word collocates. Moreover, a set of collocates are suggested when requested via the insertion of an asterisk. This interface further provides a comparison feature between collocates; additionally it provides the word's contextual use. Importantly, this interface facilitates multi-searching through a number of corpora. 


\section{Corpus of Contemporary American English (COCA)}

The Corpus of Contemporary American English (COCA) is accessible via http://corpus.byu.edu/coca/ and contains more than 600 million words of American English and covers a variety of geners such as spoken, academic texts, fiction, magazines and newspapers.

\subsection{The Use of Graded Readers}

Graded readers are sources of various reading genres which have a simplified syntax and lexis to suit different levels of L2 learners. They are a useful source of learning a second language as they expose a learner to a myriad of lexical exposure including collocations and lexical phrases. A good source for graded readers is Oxford Bookworm Graded Reader. (https://elt.oup.com/teachersclub/subjects/gradedreading/?cc=global\&selLanguage=en)

\subsection{Phrase/Collocation Dictionaries and Checkers}

Recent online dictionaries provide an availability to check a word for possible collocates. Below are three suggested collocation dictionary websites:

1- Oxford Collocation dictionary (www.freecollocation.com)

The Oxford Collocation dictionary is a user-friendly website which offers its users a wide range of collocates for the requested word. The suggested collocates are categorized based on their parts of speech (POS).

2- Ozdic collocation dictionary (www.ozdic.com)

Like Oxford dictionary, Ozdic works in the same manner by providing collocates for the designated word; the suggestions are also categorized by POS.

3- Ooz collocation dictionary (www.collocations.ooz.ie)

In a slightly different format, not only does Ooz collocation dictionary provide its users with the same features as the above mentioned collocation dictionaries, but it also provides them with a visual view of the collocates via diagrams. The diagrams connect the collocates together by arrows and a user can view the strength of a collocate based on the thickness of the arrow. Hence, this website provides learners with an effortless visual picture of the collocates allowing them to hold a wide view of the collocates and their interconnections.

\subsubsection{The Collocation Checker}

The Collocation Checker (Grami \& Alkazemit, 2016) utilizes online corpora, academic and non-academic websites for checking the appropriateness of a collocate. It provides its users with statistical view of the investigated collocate, a sample results of it as well as suggested replacements in case of inappropriate choices.

\subsubsection{Collocation Inspector}

The Collocation Inspector (Wu et al., 2010) is a useful tool which provides academic collocate suggestions for the learners. Learners can insert a text and, by accessing an 
academic reference corpus, the Collocation Inspector lists various collocates for the inappropriate ones detected in the inserted text.

\subsubsection{NetSpeak and WordGraph}

NetSpeak and WordGraph (Riehmann et al., 2011) are online interfaces which provide assistance for word choices using Google n-gram corpus. In consequence, this reflects on choice of collocates and formulae. The target audience of NetSpeak and WordGraph is learners who have doubts about phrase formations. Both interfaces act in similar ways; yet, while NetSpeak shows its results in a textual non-interactive way, the WordGraph provides a more interactive visual figure of a query where a learner can explore, filter, and expand a query. NetSpeak and WordGraph, allows a user, up to a five-word phrase, to investigate the below queries:

a. Phrase verification: A user can check how appropriate a phrase is in the English language where frequency and context of the phrase is provided.

b. Context-sensitive word choice: A user can be provided with alternatives for a given word in a phrase. This gives the user a chance to formulate appropriate sentence formulae.

c. Exploration: Allows a user to explore the context of a given word. In other words, it allows users to explore the possible words before and after the given one.

d. Comparison: allows the learner to compare between most fit of two words in certain context.

e. Similar word finder: allows a user to find similar words to their query.

f. Order checker: allows a user to check the order of a phrase.

\subsubsection{The AwkChecker}

The AwkChecker (Park et al., 2008) detects collocation errors in a text entered by a user; then, the AwkChecker, using corpus analysis, provides replacements for such errors. Those replacements are further presented with examples to assist users choose what fits their context.

\subsubsection{Collocator}

The Collocator (Wible et al., 2006) is a real-time tool which is operated online and can be used on any website to detect collocations and longer strings for the purpose of enhancing the reader's language. When detecting and highlighting collocations and chunks on a web page, the Collocator, further, provides its users with more examples for a chosen collocate/phrase.

\subsubsection{Concise Collocation Checker}

The Concise Collocation Checker (Grami \& Alkazemit, 2016), with more focus on the academic genre, searches within a range of academic websites and corpora for providing feedback for incorrect combinations as well as providing collocates/phrasal suggestions to the learner's query. It also provides a statistical view and the context for a learner's query. 


\subsubsection{Further Readings and Resources}

Biber, D., Johansson, S., Leech, G., Conrad, S., \& Finegan, E. (1999). Longman grammar of spoken and written English. London: Pearson Education Limited.

McCarthy, M., \& O’Dell, F. (2004). English phrasal verbs in use. United Kingdom: Cambridge University Press.

McCarthy, M., \& O’Dell, F. (2007). English phrasal verbs in use: Advanced. United Kingdom: Cambridge University Press.

McCarthy, M., \& O’Dell, F. (2017). English collocation in use: Intermediate (2nd ed.). United Kingdom: Cambridge University Press.

\section{References}

Altenberg, B., \& Granger, S. (2001). The grammatical and lexical patterning of MAKE in native and non-native student writing. Applied Linguistics, 22, 173-194. https://doi.org/10.1093/applin/22.2.173

Arnon, I., McCauley, S., \& Christiansen, M. (2017). Digging up the building blocks of language: Age-of-acquisition effects for multiword phrases. Journal of Memory and Language, 92, 265-280. https://doi.org/10.1016/j.jml.2016.07.004

Biber, D., Johansson, S., Leech, G., Conrad, S., \& Finegan, E. (2007). Longman Grammar of Spoken and Written English. Edinburgh Gate, England: Pearson Education Limited.

Boers, F., Eyckmans, J., Kappel, J., Stengers, H., \& Demecheleer, M. (2006). Formulaic sequences and perceived oral proficiency: Putting a lexical approach to the test. Language Teaching Research, 10, 245-261. https://doi.org/10.1191/13621688061r195oa

Bonin, P. (2004). Mental lexicon: Some words to talk about words. New York: Nova Science Publishers.

Brown, R. (1973). A first language. Cambridge: Harvard Press.

Bruza, P., Kitto, K., Nelson, D., \& McEvoyc, C. (2009). Is there something quantum-like about the human mental lexicon?. Journal of Mathematical Psychology, 53, 362-377. https://doi.org/10.1016/j.jmp.2009.04.004

Bybee, J. (2006). From usage to grammar: The mind's response to repetition. Language, 82, 711-733. https://doi.org/10.1353/lan.2006.0186

Carrol, G., \& Conklin, K. (2014). Eye-tracking multi-word units: some methodological questions. Journal of Eye Movement Research, 7(5), 1-11.

Carrol, G., \& Conklin, K. (2015). Cross language lexical priming extends to formulaic units: Evidence from eye-tracking suggests that this idea 'has legs'. Bilingualism: Language and Cognition, 1-19. https://doi.org/10.1017/S1366728915000103 


\section{Macrothink}

International Journal of Linguistics

ISSN 1948-5425

2020, Vol. 12, No. 3

Chambers, F. (1998). What do we mean by fluency?. System, 25(4), 535-544. https://doi.org/10.1016/S0346-251X(97)00046-8

Chandra, P. (2014). Teaching collocation using lexical approach as used in Made Frida Yulia's vocabulary: Lexically-based second thousands words of general service list book. Jsh Jurnal Social Humaniora, 7(2), 150-171. https://doi.org/10.12962/j24433527.v7i2.586

Clark, R. (1974). Performing without competence. Journal of Child Language, 1, 1-10. https://doi.org/10.1017/S0305000900000040

Code, C. (1994). Speech automatism production in aphasia. Journal of Neurolinguistics, 8(2), 135-148. https://doi.org/10.1016/0911-6044(94)90021-3

Daloiso. (2009). The Role of Linguistic Routines in Early Foreign Language Learning. ESE de Paula Frassinetti, 1-12. https://doi.org/10.17346/se.vol14.133

Ellis, N. C. (1996). Sequencing in SLA: phonological memory, chunking and points of order.

Studies in Second Language Acquisition, 18, 91-126. https://doi.org/10.1017/S0272263100014698

Erman, B., \& Warren, B. (2000). The idiom principle and the open choice principle. Text, 20(1), 29-62. https://doi.org/10.1515/text.1.2000.20.1.29

Evans, V., \& Green, M. (2006). Cognitive Linguistics: An Introduction. Edinburgh, Britain: Edinburgh University Press Ltd.

Gairns, R. (1986). Working with words: A guide to teaching and learning vocabulary. Cambridge: Cambridge University Press.

Grami, G. M. A., \& Alkazemit, B. Y. (2016). Improving ESL writing using an online formulaic sequence word-combination checker. Journal of Computer Assisted Learning, 32, 95-104. https://doi.org/10.1111/jcal.12115

Hakuta, K. (1974). Prefabricated patterns and the emergence of structure in second language $\begin{array}{llll}\text { acquisition. Language } & \text { Learning, 287-298 }\end{array}$ https://doi.org/10.1111/j.1467-1770.1974.tb00509.x

Hanania, E., \& Gradman, H. (1977). Acquisition of English structures: A case study of an adult native speaker in an English-speaking environment. Language Learning, 27, 75-92. https://doi.org/10.1111/j.1467-1770.1977.tb00293.x

Hatami, S. (2015, March). Teaching formulaic sequences in the ESL classroom. TESOL Journal, 6(1), 112-129. https://doi.org/10.1002/tesj.143

Hoang, H., \& Boers, F. (2016). Re-telling a story in a second language: How well do adult learners mine an input text for multiword expressions?. Studies in Second Language Learning and Teaching, 6(3), 513-535. https://doi.org/10.14746/ssllt.2016.6.3.7 


\section{Al Macrothink}

International Journal of Linguistics

ISSN 1948-5425

2020, Vol. 12, No. 3

Laufer, B., \& Waldman, T. (2011). Verb-noun collocations in second language writing: A corpus analysis of learners' English. Language Learning, 61, 647-672. https://doi.org/10.1111/j.1467-9922.2010.00621.x

Lee, N. (2004). The neurobiology of procedural memory. In J. H. Schumann, S. E. Crowell, N. E. Jones, N. Lee, S. A. Schuchert, \& L. A. Wood (Eds.), The neurobiology of learning: Perspectives from second language acquisition (pp. 43-73). Mahwah, NJ: Erlbaum.

Levelt, W. J. M. (1995). Speaking: From intention to articulation. Cambridge, Massachusetts: The MIT Press.

Levitzky-Aviad, T., \& Laufer, B. (2013). Lexical properties in the writing of foreign language learners over eight years of study: Single words and collocations. In C. Bardel, C. Lindqvist, \& B. Laufer (Eds.), L2 vocabulary acquisition, knowledge and use. New perspectives on assessment and corpus analysis (pp. 127-148). Eurosla.

Lewis, M. (1993). The lexical approach: the state of ELT and the way forward. Hove, England: language Teaching Publications.

Lewis, M. (1997). Implementing the lexical approach. Hove: Language Teaching.

Lewis, M. (2008). Implementing the lexical approach: Putting theory into practice. United Kingdom: Heinle, Cengage Learning.

Li, J., \& Schmitt, N. (2010). The development of collocation use in academic texts by advanced L2 learners: A multiple case study approach. In D. Wood (Ed.), Perspectives on formulaic language: Acquisition and communication (pp. 22-46). New York: Continuum.

Nattinger, J., \& De Carrico, J. (1992). Lexical phrases and language teaching. Bristol: Wyvern Typesetting Ltd.

Nesselhauf, N. (2005). Collocations in a learner corpus. Amsterdam/Philadelphia, The Netherlands/USA: John Benjamins. https://doi.org/10.1075/scl.14

Oxford Collocation. (n.d.). Oxford Collocation.com dictionary. Retreived January 7, 2020, from www.freecollocation.com

Ozdic. (n.d.). Retreived January 19, 2020, from www.ozdic.com

Ozz. (n.d.). Ozz.com dictionary. Retreived February 3, 2020, from www.collocations.ooz.ie

Park, T., Lank, E., Poupart, P., \& Terry, M. (2008). “Is the Sky Pure Today?” AwkChecker: An Assistive Tool for Detecting and Correcting Collocation Errors. UIST, 121-130. https://doi.org/10.1145/1449715.1449736

Pawley, A., \& Syder, F. H. (1983). Two puzzles for linguistic theory: native-like selection and native-like fluency. In J. C. Richards, \& R. W. Schmidt (Eds.), Language and communication (pp. 191-226). New York: Longman.

Pinker, S. (1999). Words and rules: The ingredients of language. New York, NY: Harper-Collins. 
Ramírez, A. (2012). The lexical approach: collocability, fluency and implications for teaching. Revista de lenguas para Fines Específicos, 18, 237-254.

Riehmann, P., Gruendl, H., Froehlich, B., Potthast, M., Trenkmann, M., \& Stein, B. (2011). The Netspeak Wordgraph: Visualizing Keywords in Context. IEEE Pacific Visualisation Symposium, 123-130. https://doi.org/10.1109/PACIFICVIS.2011.5742381

Scarcella, R., \& Karshen, S. (1978). On Routines and Patterns in Language Acquisition and Performance. Language Learning, 283-300. https://doi.org/10.1111/j.1467-1770.1978.tb00135.x

Segalowitz, S., Segalowitz, N., \& Wood, A. (1998). Assessing the development of automaticity in second language word recognition. Applied Psycholinguistics, 19, 53-67. https://doi.org/10.1017/S0142716400010572

Serrano, R., Stengers, H., \& Housen, A. (2015). Acquisition of formulaic sequences in intensive and regular EFL programmes. Language Teaching Research, 19, 89-106. https://doi.org/10.1177/1362168814541748

Sidtis, D., Canterucci, G., \& Katsnelson, D. (2009). Effects of neurological damage on production of formulaic language. Clinical Linguistics \& Phonetics, 23, 270-284. https://doi.org/10.1080/02699200802673242

Sinclair, J. (1991). Corpus, concordance, collocation. Oxford: Oxford University Press.

Siyanova, A., \& Schmitt, N. (2008). L2 learner production and processing of collocation: A multi-study perspective. Canadian Modern Language Review, 64, 429-458. https://doi.org/10.3138/cmlr.64.3.429

Siyanova-Chanturia, A., Conklin, K., \& Schmitt, N. (2011). Adding more fuel to the fire: An eyetracking study of idiom processing by native and non-native speakers. Second Language Research, 27(2), 251-272. https://doi.org/10.1177/0267658310382068

Skehan, P. (2010). Second and Foreign Language Learning and Teaching. In M. Berns, \& K. Brown (Eds.), Concise Encyclopedia of Applied Linguistics (pp. 350-357). UK: Elsevier Ltd.

Stengers, H., Boers, F., Housen, A., \& Eyckmans, J. (2010). Does chunking foster chunk uptake?. In S. De Knop, F. Boers, \& A. De Rycker (Eds.), Fostering language teaching efficiency through cognitive linguistics (pp. 99-117). Mouton de Gruyter. https://doi.org/10.1515/9783110245837.99

Ullman, M. (2005). A cognitive neuroscience perspective on second language acquisition: methods, theory, and practice. In C. Sanz (Ed.), Mind and context in adult second language acquisition (pp. 141-168). Washington, DC: Georgetown University.

Underwood, G., Schmitt, N., \& Galpin, A. (2004). The eyes have it: An eye-movement study into the processing of formulaic sequences. In N. Schmitt (Ed.), Formulaic Sequences (pp. 153-172). Amsterdam and Philadelphia: John Benjamins. https://doi.org/10.1075/1llt.9.09und 


\section{Macrothink}

International Journal of Linguistics

ISSN 1948-5425

2020, Vol. 12, No. 3

Van Lancker, D., \& Yang, S. (2017). Formulaic language performance in left- and right-hemisphere damaged patients: structured testing. Aphasiology, 31(1), 82-99. https://doi.org/10.1080/02687038.2016.1157136

Wible, D., Kuo, C., Chen, M., Tsao, N., \& Hung, T. (2006). TALN, 868-875.

Wood, D. (2001). In search of fluency: What is it and how can we teach it?. The Canadian Modern Language Review, 57(4), 573-589. https://doi.org/10.3138/cmlr.57.4.573

Wood, D. (2009). Effects of focused instruction of formulaic sequences on fluent expression in second language narratives: A case study. The Canadian Journal of Applied Linguistics, 12, $39-57$.

Wood, D. (2010). Formulaic language and second language speech fluency: Background, evidence and classroom applications. New York: Continuum.

Wray, A. (1992). The focusing hypothesis: the theory of left hemisphere lateralized language re-examined. Amsterdam: John Benjamins. https://doi.org/10.1075/sspcl.3

Wray, A. (2002). Formulaic language and the lexicon. Cambridge: Cambridge University Press. https://doi.org/10.1017/CBO9780511519772

Wu, J., Chang, Y., Mitamura, T., \& Chang, J. (2010). Automatic Collocation Suggestion in Academic Writing. Proceedings of the Association for Computational Linguists Conference Short Papers, 115-119.

Yusuf, N. H. (2016). Types of pragmalinguistic errors in the essays of Egyptian university EFL learners. Egyptian Universities Libraries Consortium. Retrieved from http://www.eulc.edu.eg/eulc_v5/Libraries/Thesis/BrowseThesisPages.aspx?fn=PublicDrawT hesis\&BibID=12464664

\section{Copyrights}

Copyright for this article is retained by the author(s), with first publication rights granted to the journal.

This is an open-access article distributed under the terms and conditions of the Creative Commons Attribution license (http://creativecommons.org/licenses/by/4.0/) 